\title{
Modeling and Controller Design of Quasi-Z-Source Inverter with Battery based Photovoltaic Power System
}

\author{
Yushan Liu ${ }^{1,3}$, Baoming Ge $\mathrm{Ge}^{1,2}$, Member, IEEE, Haitham Abu-Rub ${ }^{3}$, Senior Member, IEEE, \\ Atif Iqbal ${ }^{4}$, Senior Member, IEEE, FangZheng Peng ${ }^{2}$, Fellow, IEEE \\ ${ }^{1}$ School of Electrical Engineering, Beijing Jiaotong University, Beijing 100044, China \\ ${ }^{2}$ Department of Electrical and Computer Engineering, Michigan State University, East Lansing, MI 48824 USA \\ ${ }^{3}$ Department of Electrical and Computer Engineering, Texas A\&M University at Qatar, Doha 23874, Qatar \\ ${ }^{4}$ Department of Electrical and Computer Engineering, Qatar University, Doha 2713, Qatar \\ E-mail: yushan.liu@qatar.tamu.edu, gebaoming@tsinghua.org.cn, haitham.abu-rub@qatar.tamu.edu
}

\begin{abstract}
A Photovoltaic (PV) power generation system based on quasi-Z-Source inverter (qZSI) with energy storage is presented. A dynamic small-signal model of qZSI with battery is established. Further, the battery power and current doubleloop controllers are designed to manage the battery state of charge (SOC). Meanwhile, an improved PQ decoupling control is achieved to smooth the grid-injected power. The obtained simulation and experimental results certify the validity of the proposed control schemes, which provides an efficient method for future energy-storage PV power generation systems.
\end{abstract}

Keywords-PV system modeling; controller design; PV power system; quasi-Z-Source inverter; energy storage

\section{INTRODUCTION}

Photovoltaic (PV) energy generation has been one of the most active research areas in the past decades because of its universality, harmless, and rich persistence of this kind of energy. However, PV power is instable and susceptible to irradiation and temperature variations. Therefore, as the key component of connecting the PV panel and grid, the inverter should combine essential tasks of adjusting the output voltage of PV panel to capture the maximum power, injecting sinusoidal current into the grid, minimizing or eliminating the grid voltage fluctuations and flickers. Meanwhile, the energy storage technology is a new and important technology for future electricity system. PV system cooperating with energy storage devices through the grid-connected inverter is not only required to realize frequency and active power regulation, but also stabilize the power fluctuations of the grid, and improve the system

Part of this work, specifically Sections III and IV were supported by NPRP grant No. 09-233-2-096 from the Qatar National Research Fund (a member of Qatar Foundation). In addition, we also acknowledge support from the Beijing Jiaotong University Foundation under grant No. 2009JBM093 for Section II. The statements made herein are solely the responsibility of the authors. steady and transient performance. However, traditional inverter systems with battery energy storage usually include an extra charger circuit to exchange battery energy with the $\mathrm{DC}$ rail because the DC voltage of battery can't be injected to AC directly. Therefore, higher initial installation cost, lower efficiency, and reliability issue still block the widespread application of battery storage technology.

Z-Source inverter (ZSI) and quasi-Z-source inverter (qZSI) have been widely implemented in wind and solar power generation systems [1-4] due to their gratifying advantages, such as buck or boost of DC bus voltage without extra DC-DC circuit. In those types of inverters the power devices of same bridge arm could be turned on at the same time without being burned. This is particularly beneficial when they integrate with storage battery so that the battery voltage and current could be automatically controlled without extra charging and discharging circuitry [5]. Among studies with qZSI and battery storage [5-8], only reference [6] presented an energy management to control the battery state of charge (SOC). Another effective topology was proposed and its controller was also designed in detail [7].

As the non-linear characteristics of the circuit components, such as battery and power switching devices of three-phase inverter, qZSI with battery is a strong nonlinear system. However, when working nearby a certain steady state, the state variables of the qZSI small-signal disturbances can show linear relationships. Therefore, it is extremely important to establish small-signal dynamic model of the qZSI, which can be approximated as a linear system near the steady-state operating point. Through this way, the feedback controller can be beneficially designed. References $[9,10]$ derived the small-signal model of qZSI, while to date, no paper has studied the dynamic model for qZSI with battery. 
Accordingly, the main contributions of this paper are establishing the small-signal model of qZSI with battery, designing the effective controller according to the established model and applying it to a PV power generation system. The organization of the paper is as follows. Small-signal model of qZSI with battery is derived in section II. In Section III, the controllers are designed. Section IV demonstrates the simulated and experimental results. At last, conclusions and future work are presented in Section V.

\section{MODELING OF Q-ZSI WITH BATTERY}

The topology of the discussed qZSI with battery [5] is shown in Fig. 1. There are two working modes, as shown in Fig. 2. Fig. 2 (a) shows the shoot-through mode, in which an intentional short circuit between $\mathrm{P}$ and $\mathrm{N}$ is created and the diode is cut off by the inserted shoot-through state vector. In Fig. 2 (b), non-shoot-through mode, the inverter operates as ordinary one controlled by six active vectors and two traditional zero state vectors. The parasitic resistances $r_{\mathrm{L}}$ of inductors in quasi-Z-Source network are contained, while the series resistances of capacitors are neglected because of their small order of magnitude. For the battery model [11-13], here, a simple model with the open-circuit voltage, $V_{\mathrm{OCV}}$, and an internal resistance $R_{\mathrm{b}}$ [11] is adopted for simulating the basic function of battery. The terminal voltage of the battery model is $V_{\mathrm{b}}$, which is clamped to the voltage of capacitor 2 . The dynamic small-signal model of this equivalent circuit is built in the following.

As the relationship of capacitor- 2 voltage and battery current

$$
v_{C 2}=V_{O C V}-R_{b} i_{b}(t), \dot{v}_{C 2}(t)=-R_{b} \dot{i}_{b}(t),
$$

according to the equivalent circuit, the state space equations can be derived as

$$
F \dot{x}=\left[\begin{array}{cccc}
-r_{L} & 0 & D-1 & -D R_{b} \\
0 & -r_{L} & D & (1-D) R_{b} \\
1-D & -D & 0 & 0 \\
D & D-1 & 0 & -1
\end{array}\right] \cdot x+\left[\begin{array}{ccc}
1 & 0 & D \\
0 & 0 & 1-D \\
0 & D-1 & 0 \\
0 & 1-D & 0
\end{array}\right] \cdot u,
$$

where $x=\left[\begin{array}{llll}i_{L 1}(t) & i_{L 2}(t) & v_{C 1}(t) & i_{b}(t)\end{array}\right]^{T}, u=\left[\begin{array}{lll}v_{p}(t) & i_{d}(t) & V_{O C \nu}(t)\end{array}\right]^{T}$, $D$ represents the shoot-through time interval. Since $L_{1}=L_{2}=L$ and $C_{1}=C_{2}=C$, the coefficient matrix $F$ can be simplified to $F=\operatorname{diag}\left(L \quad L \quad C \quad R_{b} C\right)^{T}$.

In steady state, the left side of (2) is zero. Then it can be derived that

$$
\begin{aligned}
& \left\{\begin{array}{l}
V_{C 1}=\frac{1-D}{1-2 D} V_{p}+\frac{-r_{L}(1-D) I_{d}+r_{L} D I_{b}}{1-2 D} \\
V_{C 2}=\frac{D}{1-2 D} V_{p}-\frac{-r_{L}(1-D) I_{d}+r_{L} D I_{b}}{1-2 D}=V_{b}
\end{array},\right. \\
& I_{d}=\frac{(1-2 D) \cdot I_{L 1}+D \cdot I_{b}}{1-D},
\end{aligned}
$$

where $V_{\mathrm{C} 1}, V_{\mathrm{C} 2}, I_{\mathrm{b}}, I_{\mathrm{d}}, I_{\mathrm{L} 1}$ represent the steady state values. Using the small perturbance method, with $i_{L 1}-i_{L 2}=i_{B}$, after Laplace transforms, the dynamic small-signal model of qZSI with battery is derived as

$$
\left\{\begin{array}{l}
\left(L s+r_{L}\right) \hat{i}_{L 1}(s)=(D-1) \hat{v}_{C 1}(s)-D R_{b} \hat{i}_{b}(s)+\hat{v}_{p}(s)+D \hat{V}_{O C V}(s)+V_{11} \hat{d}(s) \\
C s \hat{v}_{C 1}(s)=(1-2 D) \hat{i}_{L 1}(s)+D \hat{i}_{b}(s)+(1-D) \hat{i}_{d}(s)+I_{11} \hat{d}(s) \\
\left(R_{b} C s+D\right) \hat{i}_{b}(s)=(2 D-1) \hat{i}_{L 1}(s)+(1-D) \hat{i}_{d}(s)-I_{11} \hat{d}(s)
\end{array},\right.
$$

in which $I_{11}=I_{d}-2 I_{L 1}+I_{b}, V_{11}=V_{C 1}-R_{b} I_{b}+V_{O C V}$, respectively. And $\hat{d}(s)$ represents the small perturbance of shoot-through duty ratio.

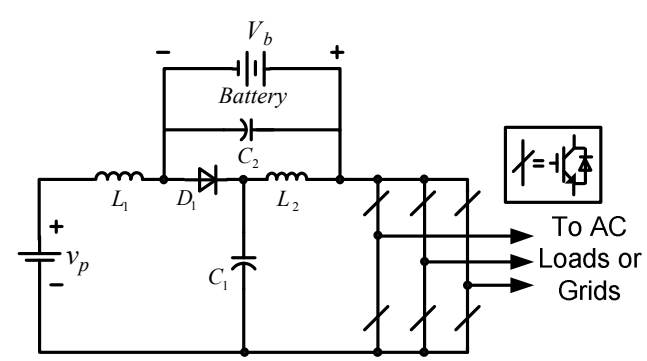

Figure 1. Quasi-Z-source inverter with battery.

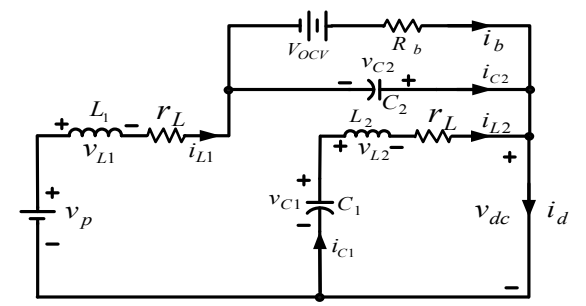

(a)

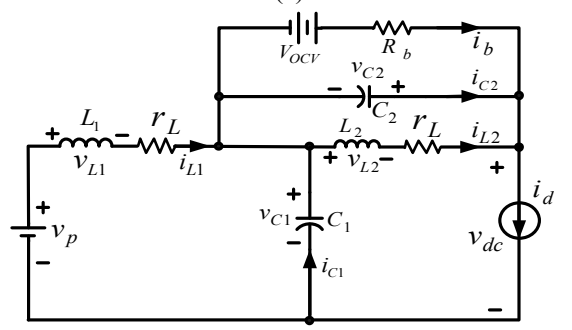

(b)

Figure 2. Equivalent circuit of qZSI with battery considering the inductor parasitic resistance. (a) Shoot-through mode. (b) Non-shootthrough mode.

\section{CONTROLLER DESIGN}

The configuration of the proposed PV power generation system based on quasi-Z-Source inverter with battery is shown in Fig. 3. The control system mainly contains doubleloop control of battery charge and discharge, PQ decoupling control of AC side, and modified SVPWM control for qZSI. The command battery power $P_{\mathrm{b}}{ }^{*}$, given by the difference of $P_{\text {out }}{ }^{*}$ and real-time PV power, generates the command battery 
current through a PI controller. Then the battery current controller, designed according to the established dynamic model, produces the shoot-through duty ratio. The active power is captured from PV panel by MPPT and capacitor-1 voltage control loop. Together with the reactive power control, the modified SVPWM control is implemented to generate gate drive signals. frequency of the being compensated transfer function, $G_{\mathrm{ibd}}(\mathrm{s})$. As it is known, if the crossover frequency towards to low frequency, the system stability can be improved, but the fast follower characteristics will decline; if the crossover frequency shifts to the corner frequency, the fast follower characteristics can be improved, but the system stability margin will decline. Therefore, the crossover frequency of

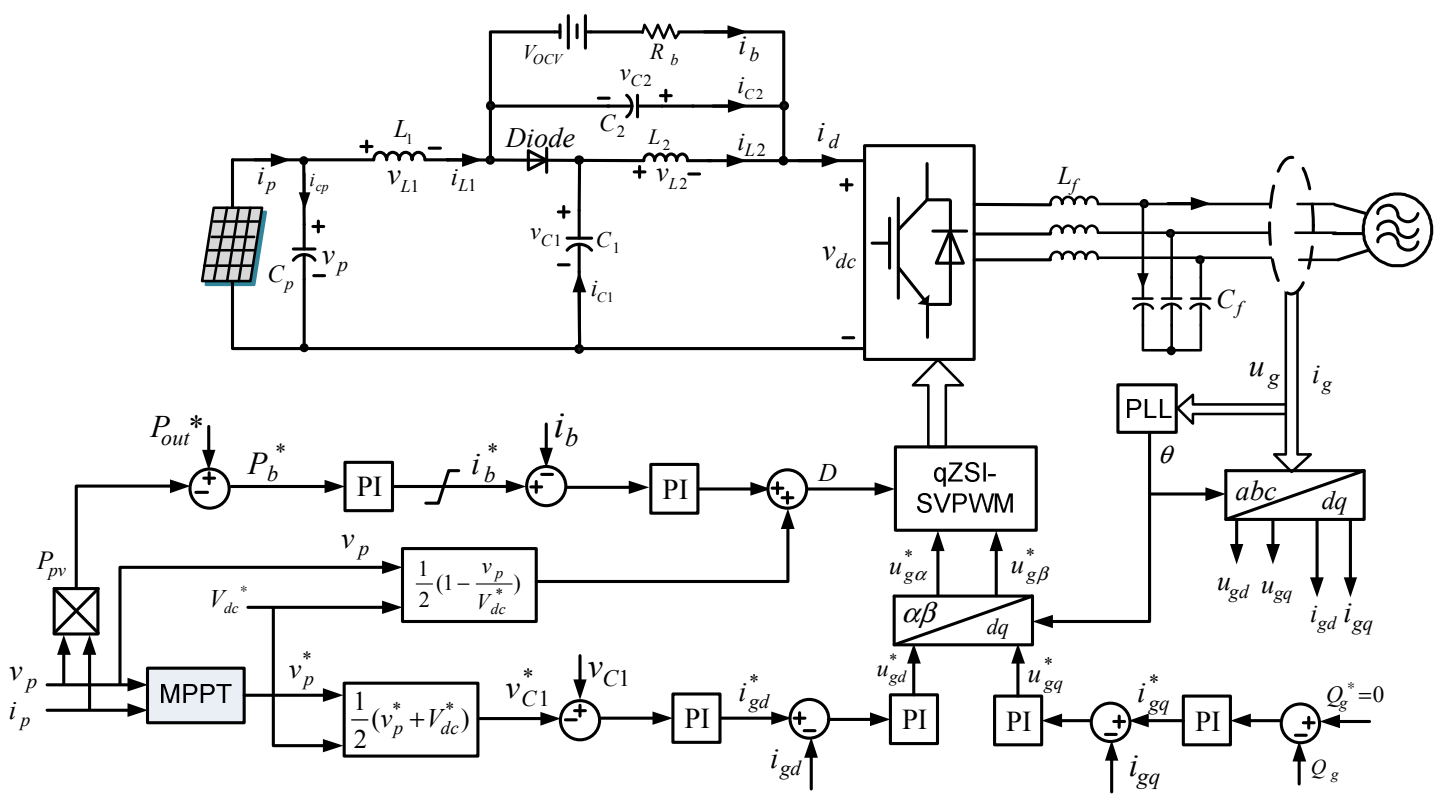

Figure 3. The proposed PV power generation system.

\section{A. Double-loop Control of Battery Charge and Discharge}

\section{1) Inner-loop battery current control}

From (4), the signal flow chart is obtained, as shown in Fig. 3. Thus, by Mason's gain rule, the open-loop transfer function from battery current to shoot-through duty ratio can be solved as

$$
G_{i b d}(s)=\frac{\hat{i}_{b}(s)}{\hat{d}(s)}=\frac{-s L I_{11}+(2 D-1) V_{11}-r_{L} I_{11}}{R_{b} L C s^{2}+\left(L D+C R_{b} r_{L}\right) s+\left[D r_{L}+R_{b}(1-2 D)^{2}\right]} .
$$

From (5), it can be obtained that $G_{\text {ibd }}(\mathrm{s})$ has a RHP (right half plane) zero. To weaken its influence, a PI controller is employed. After compensation, the open-loop transfer function becomes

$$
\begin{aligned}
G_{\text {oibd }}(s)= & \frac{s k_{p_{\_} i d}+k_{i_{-} i d}}{s} \\
& \cdot \frac{-s L I_{11}+(2 D-1) V_{11}-r_{L} I_{11}}{R_{b} L C s^{2}+\left(L D+C R_{b} r_{L}\right) s+\left[D r_{L}+R_{b}(1-2 D)^{2}\right]}
\end{aligned}
$$

from which it can be seen the order of the system is enhanced by adding an open-loop pole at the origin, improving the steady-state performance; and a negative open-loop real zero is increased to reduce the damping of the system and ease the adverse effects on the system stability and dynamic performance, which is generated by the pole of PI controller. The zero of the PI controller is set to the corner
$G_{\text {oibd }}(\mathrm{s})$ is set to one-tenth corner frequency of $G_{\text {ibd }}(\mathrm{s})$. Then the controller parameters can be solved as $k_{p_{-} i d}=-2.1077 \mathrm{e}-5$, $k_{i \text { id }}=-0.2649$. With the system specifications listed in Table I, the Bode plots of the open-loop transfer function for battery current controller can be obtained, as shown in Fig. 5. It can be seen that after compensation, the amplitude-frequency characteristic curve decreases at $-20 \mathrm{~dB} / \mathrm{dec}$ in low frequency; and carry on falling at $-40 \mathrm{~dB} / \mathrm{dec}$ after the corner frequency of $G_{\mathrm{ibd}}(\mathrm{s})$, consequently ensuring the damping of the function in high frequency. To get fast response, the feed forward $d^{*}$ is employed, which can be determined by the inherent relationship of qZSI between $v_{\mathrm{p}}$ and $V_{\mathrm{dc}}$, that is $d^{*}=\frac{1}{2}\left(1-\frac{v_{p}}{V_{d c}{ }^{*}}\right)$.

TABLE I. SPECIFICATIONS OF THE Q-ZSI WITH BATTERY SYSTEM.

\begin{tabular}{l|l}
\hline \multicolumn{1}{c|}{ Parameters } & Values \\
\hline$L$, Inductance of Q-ZSI & $500 \mu \mathrm{H}$ \\
$r_{\mathrm{L}}$, Parasitic resistance of inductor & $0.15 \Omega$ \\
$C$, Capacitance of Q-ZSI & $470 \mu \mathrm{F}$ \\
$V_{\mathrm{OCV}}$, Voltage of Battery & $12 \mathrm{~V}$ \\
$R_{\mathrm{b}}$, Internal Resistance of Battery & $0.45 \Omega$ \\
$I_{\mathrm{d}}$, Average DC-link Current & $11 \mathrm{~A}$ \\
$v_{\mathrm{p}}$, DC voltage of PV Panel & $255 \mathrm{~V}$ \\
\hline
\end{tabular}




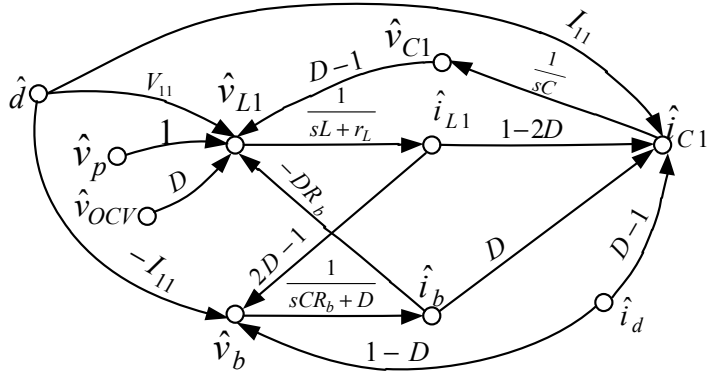

Figure 4. Signal flow chart of qZSI with battery.

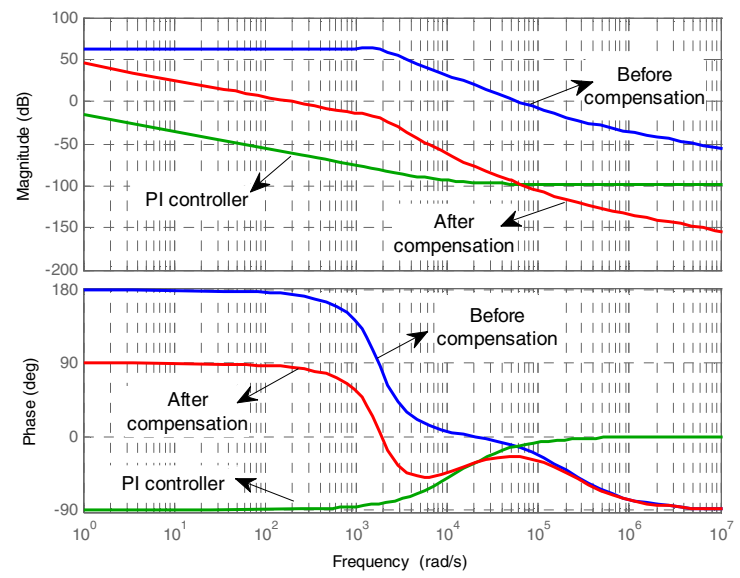

Figure 5. Bode plots for battery current controller.

\section{2) Outer-loop power control}

The command battery current is given by the outer system power control. During one switching cycle, the average PV power, battery power, and output power are

$$
\begin{gathered}
P_{p v}=V_{p} \cdot i_{L 1}, P_{b}=V_{b} \cdot i_{b}, \\
P_{\text {out }}=V_{d c} \cdot I_{d}=(1-D) \cdot \hat{v}_{d c} \cdot I_{d}+D \cdot 0=\frac{1-D}{1-2 D} V_{p} \cdot I_{d},
\end{gathered}
$$

where $\hat{v}_{d c}=1 /(1-2 D) V_{p}$, which is the maximum value of DC-link voltage. Substitute (2) into (8), it can be derived that $P_{\text {out }}=P_{p v}+P_{b}$. That is $P_{b}=P_{\text {out }}-P_{p v}$.

Thus, when the command output power, $P_{\text {out }}{ }^{*}$, is limited by SOC to protect the battery from over charge and over discharge [6], the command battery power will change along with the PV panel output power fluctuations in the following three cases: (i) When PV panel output power is relatively stable, that is $P_{\mathrm{pv}}=P_{\text {out }}{ }^{*}$, all of the PV power delivers to the grid; almost no energy flows in energy storage battery. (ii) When PV power falls suddenly, that is $P_{\mathrm{pv}}<P_{\text {out }}{ }^{*}$, the storage battery will release energy to compensate the abrupt falling of PV panel output power. (iii) When PV power increases, that is $P_{\mathrm{pv}}>P_{\text {out }}$, the battery will be charged to absorb the redundant power of PV panel. Thereby, the controller can not only control the battery SOC, but also smooth out the PV power.

\section{B. AC-side Output Control}

The common PQ decoupling control is improved to obtain maximum active power from PV panel and compensate reactive power, as shown in Fig. 3. Considering the easy implementation and excellent tracking efficiency [14], the perturbation and observation ( $\mathrm{P} \& \mathrm{O})$ maximum power point tracking (MPPT) strategy is employed.

Ulteriorly, the attained maximum power point (MPP) voltage, as well as the command dc-link voltage are used to generate the command capacitor- 1 voltage by $V_{\mathrm{C} 1}{ }^{*}=\left(v_{\mathrm{p}}{ }^{*}+\right.$ $\left.V_{\mathrm{dc}}{ }^{*}\right) / 2$. And the inner-loop d-axis current is given by $i_{\mathrm{gd}}{ }^{*}=G_{P I-i v}(\mathrm{~s})\left(V_{\mathrm{C} 1}-V_{\mathrm{C} 1}{ }^{*}\right)$ to increase the active power injected to the grid when the error is positive [15]. The reactive power is set to zero in our situation.

For the control of qZSI, as the shoot-through states need to be inserted into the traditional PWM method, the traditional space vector PWM (SVPWM) control, with high utilization rate of the voltage and the low harmonics effects, is modified to control the qZSI, called as qZSI-SVPWM. There are three kinds of qZSI-SVPWM [16]-[18]. The novel modified space vector PWM technique using six shootthrough states within a switching period is applied to generate gate drive signals for qZSI switches [16].

\section{SimUlated AND EXPERIMENTAL INVESTIGATION}

\section{A. $\quad$ Simulated Results}

Based on the aforementioned PV power generation system, simulation is performed in MATLAB / SIMULINK. Among the common energy storage batteries, such as leadacid battery, nickel-metal hydride battery, and lithium ion battery, a lead-acid battery is chosen in view of its abundant resources, recyclable, and reliable performance.

The parameters are the same as Table I. And the simulated PV power characteristic curve is shown in Fig. 6. The command dc-link voltage, $V_{\mathrm{dc}}{ }^{*}$, is set to $400 \mathrm{~V}$, and command system output power, $P_{\text {out }}{ }^{*}$, is set to $3000 \mathrm{~W}$. At first, the irradiation and temperature conditions are $25{ }^{\circ} \mathrm{C}$, $1000 \mathrm{~W} / \mathrm{m}^{2}$. At $0.5 \mathrm{~s}$, they changed to $50{ }^{\circ} \mathrm{C}, 800 \mathrm{~W} / \mathrm{m}^{2}$. The simulation results are partly shown in Fig. 7.

Through comparing the PV voltages in Figs. 6 and 7 (a), it can be seen that the PV panel always works at its MPP although the irradiation and temperature change. Fig. 7 (b) indicates that when the PV output power decreases, the shoot-through duty ratio, controlled by battery power and current controller, increases, getting more power from battery to compensate the low PV power. On the other hand, in Fig. 7 (c), the capacitor-1 voltage reduces, reflecting the reduction of the active power delivered to the grid. Figs. 7 (d) and (e) show that when the PV power is the same as $P_{\text {out }}{ }^{*}$, all 
of the PV panel output power is delivered to the grid, the battery is non-charging and non-discharging, that is $P_{\mathrm{B}}=0$, $i_{\mathrm{b}}=0$; when the PV power decreases, the battery is discharging to keep the grid power constant, that is $P_{\mathrm{b}}>0$, $i_{\mathrm{b}}>0$. Consequently, the simulated results demonstrate the validity of the proposed control schemes.

A prototype is being built to verify the proposed PV power generation system. And some initial results without battery have been obtained, shown in Fig. 8. In the final paper, more satisfactory results with battery will be updated.

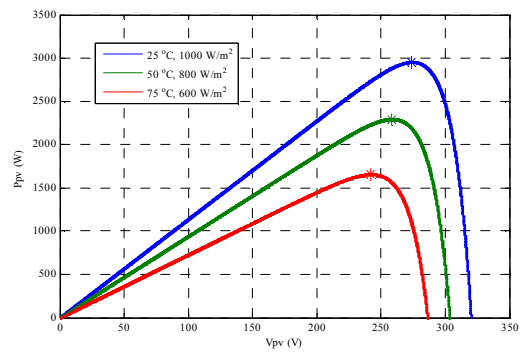

Figure 6. PV power characteristic.

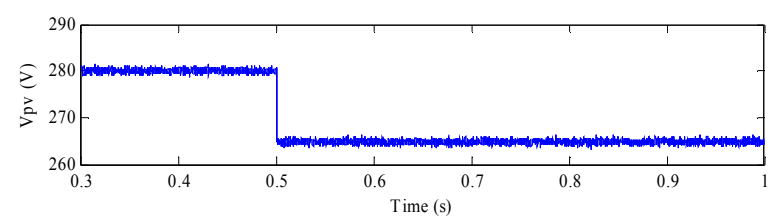

(a)

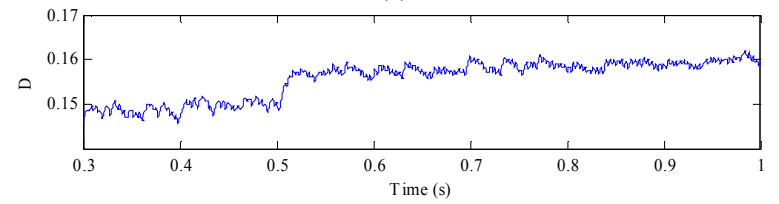

(b)

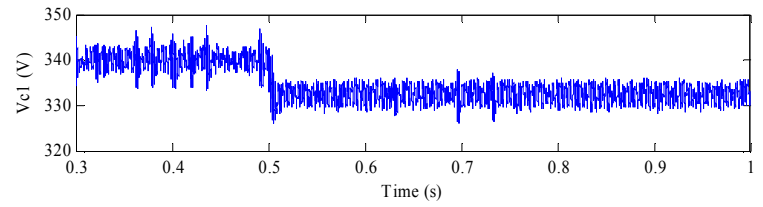

(c)

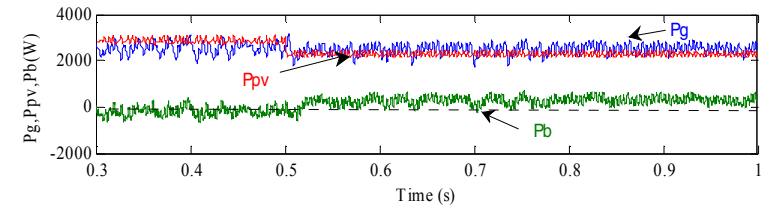

(d)

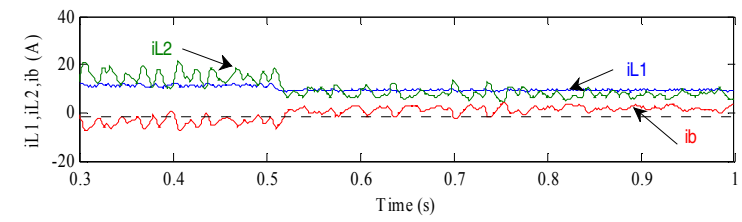

(e)

Figure 7. Simulated results. (a) PV panel output voltage. (b) Shoot-though duty ratio. (c) Capacitor-1 voltage. (d) PV panel, grid, and battery power. (e) Inductor-1, inductor-2, and battery current.

\section{B. Experimental Verification}

A 3-kW hardware prototype is built for implementing the proposed PV power generation system, shown in Fig. 8. The PM50CLA120 IPM (Intelligent Power Module) is adopted as power switches; the control core is based on TMS320F28335 DSP; and the energy storage battery is a $12-\mathrm{V}$ Lead-Acid battery, BP7-12. A DC power supply with a $2 \Omega / 200 \mathrm{~W}$ high-power golden-aluminum shell resistor, shown in Fig. 8, has been used to simulate a solar panel, whose power is 40 $\mathrm{W}$, voltage is $17.3 \mathrm{~V}$, and current is $2.31 \mathrm{~A}$ at MPP under STC (Standard Test Conditions, $1000 \mathrm{~W} / \mathrm{m}^{2}, 25{ }^{\circ} \mathrm{C}$ ). The other circuit parameters are the same as that of Table I.

The working condition of high PV panel output power that is battery charging was performed, as the results shown in Fig. 9. From the former statements, it should satisfy $i_{\mathrm{b}}<0$ and $i_{\mathrm{L} 1}<i_{\mathrm{L} 2}$. Seen from Fig. 9 (a), it can be obtained that the results are in accordance with the theoretical analysis. From Fig. 9 (b), it can be seen that the system always meets the basic relationships of qZSI, such as $V_{\mathrm{C} 1}+V_{\mathrm{C} 2}=V_{\mathrm{dc}}$. Furthermore, the grid-connected current is verified to be exactly in phase with grid voltage, shown in Fig. 9 (c), realizing connecting to the grid with unity power factor.

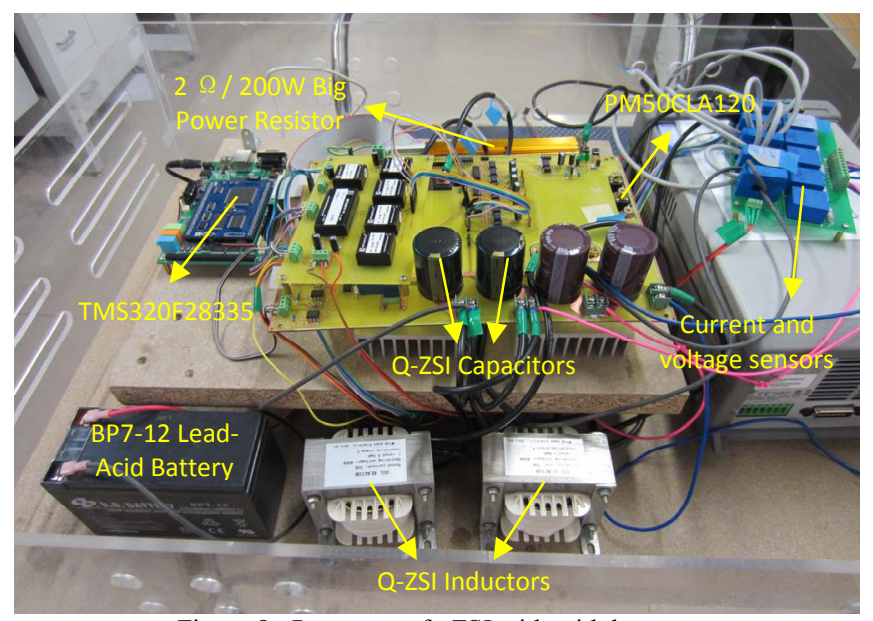

Figure 8. Prototype of qZSI with with battery.

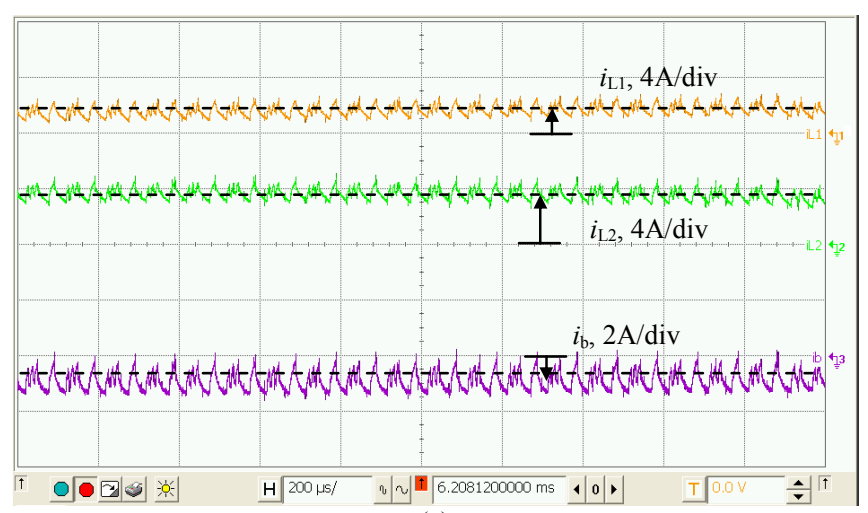

(a) 

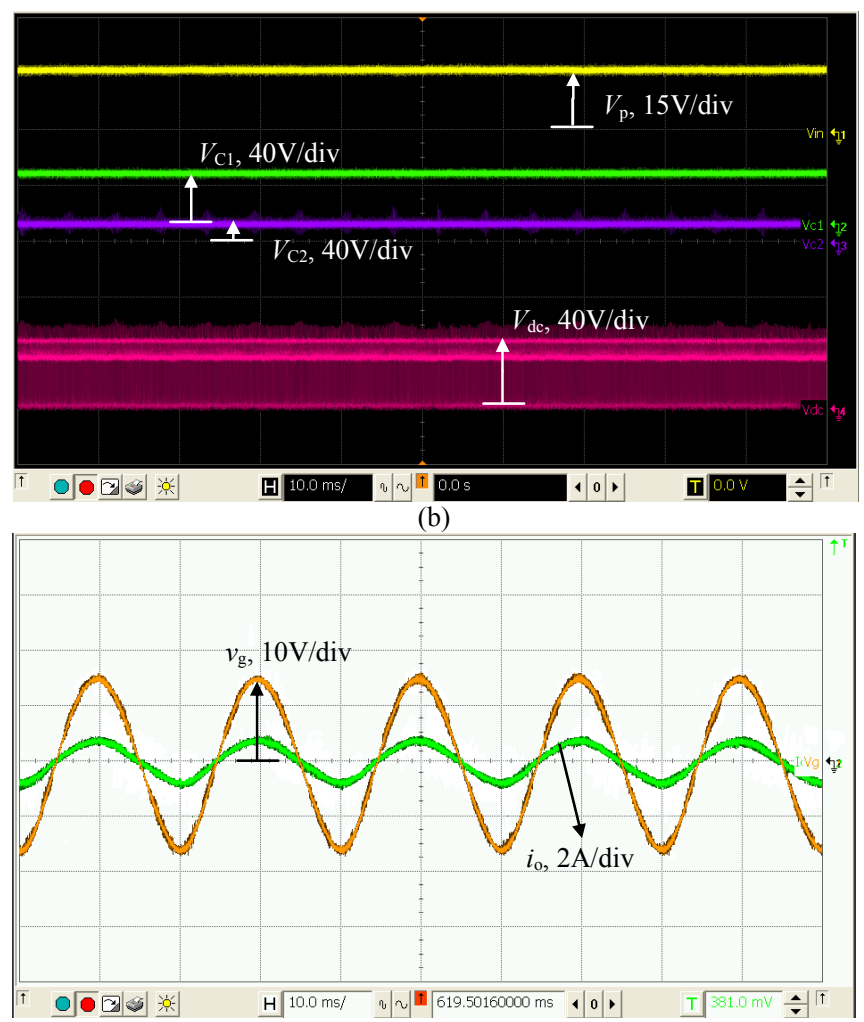

(c)

Figure 9. Experimental results. (a) inductor-1, inductor-2 and battery current; (b) PV, capacitor-1, capacitor-2 and dc-link voltage; (c) one phase grid voltage and grid-connected current.

\section{CONCLUSIONS}

A PV power generation system based on qZSI with energy storage battery was presented in this paper. A dynamic small-signal model of qZSI with battery was established. According to the derived model, the battery power and current based controller was designed to realize the battery charging and discharging. The AC-side output power control was proposed to capture the maximum power from PV panel and smooth the grid-connected power by improving the usual PQ decoupling control method. The correctness and effectiveness of the proposed controllers were verified by both the simulation and experimental results.

\section{REFERENCES}

[1] Y. Li, et al., "Quasi-z-source inverter for photovoltaic power generation systems," in 24th Annual IEEE Applied Power Electronics Conference and Exposition, APEC 2009, February 15, 2009 February 19, 2009, Washington, DC, United states, 2009, pp. 918924.

[2] P. Jong-Hyoung, et al., "Grid-connected PV System Using a Quasi-Zsource Inverter," in Applied Power Electronics Conference and Exposition, 2009. APEC 2009. Twenty-Fourth Annual IEEE, 2009, pp. 925-929.

[3] D. M. Vilathgamuwa, et al., "Z-source Converter Based Gridinterface For Variable-speed Permanent Magnet Wind Turbine Generators," 2008 Ieee Power Electronics Specialists Conference, Vols 1-10, pp. 4545-4550,4824,2008.
[4] S. M. Dehghan, et al., "A New Variable-Speed Wind Energy Conversion System Using Permanent-Magnet Synchronous Generator and Z-Source Inverter," Ieee Transactions on Energy Conversion, vol. 24, pp. 714-724, Sep 2009.

[5] J.G. Cintron-Rivera, Yuan Li, Shuai Jiang, F.Z. Peng, "Quasi-ZSource inverter with energy storage for Photovoltaic power generation systems," Applied Power Electronics Conference and Exposition (APEC), 2011 Twenty-Sixth Annual IEEE, vol., no., pp.401-406, 6-11 March 2011.

[6] Dongsen Sun; Baoming Ge; Abu Rub, H.; Peng, F.Z.; de Almeida, A.T.; , "Power flow control for quasi-Z source inverter with battery based PV power generation system," Energy Conversion Congress and Exposition (ECCE), 2011 IEEE, vol., no., pp.1051-1056, 17-22 Sept. 2011.

[7] Baoming Ge, Qin Lei, Fang Zheng Peng, Dongsen Song, Yushan Liu, Haitham A.R., "An effective PV power generation control system using quasi-Z source inverter with battery," Energy Conversion Congress and Exposition (ECCE), 2011 IEEE, vol., no., pp.10441050, 17-22 Sept. 2011.

[8] Fenglin Li, Baoming Ge, Dongsen Sun, Daqiang Bi, Fang Zheng Peng, Haitham A.R., "Quasi-Z source inverter with battery based PV power generation system," Electrical Machines and Systems (ICEMS), 2011 International Conference on, vol., no., pp.1-5, 20-23 Aug. 2011.

[9] Poh Chiang Loh, Vilathgamuwa, D. Mahinda, et al., "Transient modeling and analysis of pulse-width modulated Z-source inverter," IEEE Transactions on Power Electronics, v 22, n 2, pp. 498-507, March 2007.

[10] M. Shen, et al., "Modeling and controller design of the Z-source inverter with inductive load," 2007 IEEE Power Electronics Specialists Conference, Vols. 1-6, pp. 1804-1809, 2007.

[11] M. Ceraolo, "New dynamical models of lead-acid batteries," Power Systems, IEEE Transactions on, vol.15, no.4, pp.1184-1190, Nov 2000.

[12] O. Tremblay, L.-A. Dessaint, A.-I. Dekkiche, "A Generic Battery Model for the Dynamic Simulation of Hybrid Electric Vehicles," Vehicle Power and Propulsion Conference, 2007. VPPC 2007. IEEE, vol., no., pp.284-289, 9-12 Sept. 2007.

[13] Shuhui Li; Bao Ke; , "Study of battery modeling using mathematical and circuit oriented approaches," Power and Energy Society General Meeting, 2011 IEEE, vol., no., pp.1-8, 24-29 July 2011.

[14] C Hua, J L in, "A modified tracking algorithm for maximum power tracking of solar array," Energy Conversion and Management, vol. 6, no. 45, pp.911-925, 2004.

[15] Jong-Hyoung Park, Heung-Geun Kim, Eui-Cheol Nho, Tae-Won Chun, "Capacitor voltage control for MPPT range expansion and efficiency improvement of grid-connected Quasi Z-Source Inverter," Power Electronics Conference (IPEC), 2010 International, vol., no., pp.927-931, 21-24 June 2010.

[16] Yushan Liu, Baoming Ge, Fernando J. T. E. Ferreira, Anibal T. de Almeida, Haitham Abu-Rub, "Modeling and SVPWM control of quasi-Z-source inverter," Electrical Power Quality and Utilisation $(E P Q U), 2011$ 11th International Conference on, vol., no., pp.1-7, 17-19 Oct. 2011.

[17] M. Von Zimmermann, et al., "Z-source drive inverter using modified SVPWM for low output voltage and regenerating operation," in 2009 13th European Conference on Power Electronics and Applications, EPE '09, September 8, 2009 - September 10, 2009, Barcelona, Spain, 2009.

[18] Li Tingyuan, Zheng Jianyong, You Jun, et al.,"Study on a Modified Space Vector PWM Technique based on Z-Source Inverter,"Telecom Power Technology, v 26, n5, pp. 1-5, 2009. 